\title{
Is there convergence of national environmental policies? An analysis of policy outputs in 24 OECD countries
}

\author{
Katharina Holzinger ${ }^{\mathrm{a} *}$, Christoph Knill ${ }^{\mathrm{a}}$ and Thomas Sommerer ${ }^{\mathrm{b}}$ \\ ${ }^{a}$ Department of Politics and Public Administration, University of Konstanz, Konstanz, \\ Germany; ${ }^{b}$ Department of Political Science, Stockholm University, Stockholm, Sweden
}

\begin{abstract}
A central issue of globalisation research is the question whether globalisation leads to the convergence of policies or whether domestic responses to global challenges remain strongly influenced by existing domestic structures. In the field of environmental policy, there is some analysis of the diffusion of policy innovations, but there is a lack of systematic knowledge as to whether this leads to policy convergence at a broad scale. To what extent does environmental policy convergence take place? The analysis of policy development uses a data set covering 22 different environmental policy measures in 24 OECD countries from 1970 to 2005 . It reveals increases in the similarity of individual policies across countries, in the homogeneity of their policy repertoires and, particularly, in the strictness of regulations, as well as processes of catching up and overtaking among countries.
\end{abstract}

Keywords: environmental policy; convergence; diffusion; harmonisation; competition; globalisation

\section{Introduction}

One of the key issues of globalisation research in the social sciences is the question whether globalisation leads to the convergence of political institutions, policies, the legal order and societal structures (Guillén 2001, p. 235). Is the world becoming ever more similar as a result of globalisation and Europeanisation as the 'world society approach' (Meyer et al. 1997) implies? Does the strong growth of economic and institutional inter-linkages between nation states lead to increasingly similar policy measures and institutions across countries (see, for example, Barrios et al. 2003, Jahn 2006, Swank 2006, Volden 2006)? Or is convergence emerging from globalisation and European integration unlikely because domestic responses to global or European

\footnotetext{
*Corresponding author. Email: katharina.holzinger@uni konstanz.de
} 
challenges are strongly influenced by existing domestic structures and institutions (see, for example, Dimitrova and Steunenberg 2000, Knill 2001, Kahler and Lake 2003)?

The environmental field is of particular analytical and practical interest when addressing these questions. First, there is some research suggesting that cross-national diffusion of environmental policy innovations regularly occurs (for example, Busch et al. 2005). But does this really represent an overall trend leading to greater homogeneity of national environmental policies? Second, theories of regulatory competition claim that economic globalisation might drive the level of regulatory strictness downwards (Oates and Schwab 1988), whereas Vogel (1995) shows that cross-border competition might even lead to upward movements of environmental standards. To date, there is very limited systematic knowledge about the direction of potential convergence trends. Can we observe an overall tendency of strengthening or weakening regulatory requirements? Third, even if we had information on the direction of convergence, we still would not know whether regulatory strengthening is merely the result of dynamics in environmental pioneer countries, with the socalled laggards remaining stuck at the bottom. This question refers to mobility, i.e. the extent to which convergence coincides with processes of catching-up and changing rank between leaders and laggards.

It was, hence, the objective of this article to investigate whether and to what extent convergence in environmental policy actually takes place. At first glance, one might argue that this question has already been answered, given the findings of our earlier studies (Holzinger et al. 2008a,b). However, these studies predominantly focused on a distinctive concept as well as a way of measuring convergence, based on a dyadic approach to measuring changes in policy similarity of country pairs over time. Although it was also shown that the evaluation of convergence might vary in light of the distinctive concept of convergence (Holzinger 2006), so far no analysis exists that systematically explains and compares convergence developments in light of different concepts and measurement approaches. Moreover, the issue of mobility has not yet been extensively covered. Finally, this article is based on new data for those environmental policies that can be measured at a metric level: we use a complete time series from 1970 to 2005 , which gives a better picture for the aspects of direction and mobility.

Against this backdrop, our focus is on three different dimensions of convergence (Heichel et al. 2005), namely homogeneity, direction and mobility. First, with respect to homogeneity, we are interested in the extent to which the domestic policy repertoires (the portfolio of environmental policy measures of a country) and levels of regulatory standards have become more similar over time. Second, we look at the direction of domestic policy changes. Have environmental policies become stricter over time and have the countries under investigation developed in a similar way? Third, we analyse whether and to what extent laggard countries have caught up with leaders or even have overtaken former frontrunners. We analyse the policy development by relying 
on a data-set that covers 22 different environmental policy measures in 24 member countries of the OECD from 1970 to 2005 .

We proceed as follows. In the next section, we provide a theoretical discussion on potential reasons and factors that affect the degree of environmental policy convergence across the countries under study. Based on this discussion, we suggest several conjectures ${ }^{1}$ on expected convergence developments with regard to the dimensions of homogeneity, direction and mobility. In Section 3, we present empirical evidence on each convergence dimension. Section 4 summarises our findings and discusses the general implications of our study.

\section{Conjectures on environmental policy convergence}

In this section, we develop conjectures on expected patterns of environmental policy convergence with regard to the dimensions of homogeneity, direction and mobility. For each convergence dimension, we derive a set of expectations whose plausibility will be illustrated by the analysis of aggregate data in the subsequent empirical chapters.

We focus our discussion along the central causes of cross-national policy convergence. In the literature, a broad number of potential causes of policy convergence are identified. Although there is considerable overlap, the type and number of identified mechanisms strongly vary, depending on the underlying theoretical focus. In view of this conceptual variety, we concentrate on the analysis of two mechanisms that are generally considered as major driving forces of environmental policy convergence: international harmonisation and regulatory competition (Holzinger and Knill 2005).

\subsection{Convergence effects of international harmonisation}

As a result of international agreements, national governments are legally required to adopt policies and programs (Bennett 1991, p. 225). This mechanism is traced to the existence of interdependencies, which push governments to resolve common problems through cooperation within international institutions, hence sacrificing some independence for the good of the community. Although the achievement of harmonised rules can hardly be taken for granted in view of different national interests and political cultures, once established institutional arrangements will constrain and shape domestic policy choices, even as they are constantly challenged and reformed by their member states (Martin and Simmons 1998, p. 743).

There are several general conditions that affect the effectiveness of this mechanism in bringing about cross-national policy convergence. First, it is obvious that convergence effects can only be expected amongst the member countries of the corresponding regime with obligatory potential. Moreover, the converging impact of legal requirements depends on the capacities of the international institution to enforce legally binding rules and, related to this 
issue, the compliance by the member states. It is well documented in the literature that international institutions and regimes reveal big differences not only in terms of the size of their membership, but also in their enforcement capacities.

In this study, however, the focus is not so much on assessing the differential impact of varying international institutions, but on the analysis of general trends in global environmental policy developments. We, therefore, concentrate only on those characteristics of international harmonisation that make a difference for convergence across different policy types rather than convergence effects across different international institutions or country groups. This approach is also justified by the fact that we investigate policy developments for a sample of OECD countries that - in terms of membership in international environmental institutions - reveals a rather homogenous pattern.

\subsubsection{Policy homogeneity}

What are the effects of international harmonisation on potential increases or decreases in the homogeneity of national environmental policies over time? At the most general level, there are good reasons to expect an overall tendency towards an increase in policy homogeneity across countries. This expectation is based on the fact that over time there is a profound increase in activities of harmonisation of national policies through international and, in particular, EU law (Zürn 1998, Knill 2008). This general statement, however, needs further differentiation in light of the dimension and type of environmental policies.

First, for the policy dimension, a basic distinction has to be made between the adoption of a certain policy and the concrete calibration of these policies. The latter refers to what Hall (1993) has called policy settings; i.e. the level of regulatory stringency inherent to a certain policy that becomes most clearly apparent in the level of environmental standards or limit values. We expect significant differences in the degree of convergence across the two dimensions, as they imply different requirements with regard to the classification as 'similar' or 'dissimilar' policy. For the dimension of policy adoptions, similarity is already given as soon as the countries in question adopt a political program in response to a specific problem, regardless of the concrete instruments or goals defined in the program. The similarity requirement is much more demanding, however, when it comes to the dimension of settings, implying that countries have not only adopted the same policies, but also that these policies are based on similar instruments and their similar 'tuning' (in terms of similar standard levels or tax rates). We, thus, expect less convergence for exact settings than for the simple adoption of measures.

Second, the degree of homogeneity increase is also likely to vary across different policy types. With regard to the effects of international harmonisation, a distinction has to be made between the subgroups of obligatory and non-obligatory policies; i.e. policies for which legally binding requirements at 
the international or supranational level are present or absent. Convergence will be more pronounced in the former case, given the legal obligation for the signatory countries to adopt a certain policy or adjust respective standard levels agreed upon in international or European negotiations (Holzinger and Knill 2008).

\subsubsection{Direction of convergence}

What are our expectations with regard to the direction of convergence? To what extent do the expected increases in policy homogeneity coincide with upward or downward changes in levels of regulatory stringency? While factors like technological progress (which reduces economic costs for complying with stricter standards), increasing environmental awareness, as well as increasing environmental problems generally suggest that regulatory stringency should increase over time, several qualifications to this statement apply in the light of different policy types.

First, especially for harmonisation at the level of the EU, additional structural features of the policy-making process might favour an upward shift. The fact that we observe European harmonisation at the top rather than the bottom of existing member state regulations also in these areas (cf. Knill 2003, p. 73-88) has been explained by particular dynamics emerging from a regulatory contest in influencing EU policies between the member states (Héritier et al. 1996). These dynamics emerge from the interest of national governments in minimising the institutional costs of adjusting domestic regulatory arrangements to EU policy requirements. Especially, high-regulating countries with a comprehensively and consistently developed regulatory framework of environmental instruments might face considerable problems of adjustment, if European policies reflect regulatory approaches that depart from domestic arrangements. As a result, these countries have a strong incentive to promote their own concepts at the European level. The most promising way is to rely on the strategy of the 'first move'; i.e. to try to shape European policy developments already during the stages of problem-definition and agendasetting. This requires that member states have to win the support of the EU Commission, which has the formal monopoly to initiate policies at the EU level. The Commission, in turn, is generally interested in extending supranational policy competencies. This specific interaction of national and supranational interests favours the development of innovative and ambitious policies at the EU level (Knill 2003, p. 131-134).

Second, even if we only assume that the final agreement lies in the middle between high-regulating and low-regulating countries, there is still a high probability that the mean of national regulatory levels becomes stricter. This can be traced to the fact that by far the largest part of environmental standards follows the principle of minimum rather than total harmonisation. In the case of minimum harmonisation, it is still possible for countries with a preference for higher regulatory levels to enact standards beyond the level specified in 
international agreements. In contrast to total harmonisation, deviations to the top are, therefore, still possible, while countries with lower standards are obliged to raise their standards to the international minimum level. Given the dominance of minimum harmonisation, we, thus, predict that international environmental policy cooperation is likely to result in shifting the regulatory mean upwards. This expectation rests on the assumption that high-regulating countries will not lower their standards towards the minimum level.

\subsubsection{Mobility: dynamics of catching-up}

To what extent can we expect that laggard countries increase their regulatory standards faster than environmental leader countries, hence catching-up with or even overtaking the frontrunners? Or, by contrast, can we also conceive of exactly opposite scenarios in which leader countries are falling back behind the former laggards? The dynamics of overtaking and catching-up might be strongly affected by international harmonisation, implying that mobility dynamics should be more pronounced for obligatory than for non-obligatory policies. These effects emerge from the fact the involved states are legally required to adjust their regulatory settings to the level specified in international or EU law. In the case of minimum harmonisation, the countries might still go beyond the specified level, while for total harmonisation all countries have to implement the harmonised standard. In the latter case, it is obvious that compliance with international law coincides with a process of catching-up; i.e. countries below the harmonised level have to increase their standards, while countries with stricter rules have to adopt less-stringent arrangements. However, even in cases of minimum harmonisation, we can expect processes of catching-up, assuming that harmonisation takes place at a level that is closer to the leader than the laggard countries. This way, laggards are legally obliged to move closer to the leaders, at least up to the level at which the minimum standard has been set (Holzinger and Knill 2004).

\subsection{Convergence effects of regulatory competition}

Regulatory competition is generally expected to emerge as a result of economic integration. With the increasing integration of global markets and the abolition of national trade barriers, the international mobility of goods, workers and capital puts pressure on national governments to redesign domestic market regulations to attract foreign investment and to avoid regulatory burdens restricting the competitiveness of domestic industries threatening to shift their activities elsewhere. This way, regulatory competition among governments may lead to a race to the bottom in environmental policy, implying policy convergence at the lowest common denominator: states will gravitate towards the regulatory level of the most laissez-faire country (Drezner 2001, p. 59). 
From theories of regulatory competition (e.g. Vogel 1995, Scharpf 1997 , Holzinger 2003), several expectations about the convergence effects of this mechanism can be derived. Regarding homogeneity, the basic expectation is that policy similarity across countries increases with the extent to which they are exposed to competitive pressures. It follows from this argument that convergence effects can only be expected if a country is exposed to international market pressures. As we are less interested in differences across countries, but across dimensions and types of policies, we - similar to the discussion on international harmonisation - do not further elaborate on this aspect.

\subsubsection{Policy homogeneity}

During recent decades, massive attempts at economic integration and market liberalisation have taken place, in particular at the level of the EU and the World Trade Organisation (WTO). From this development, it follows that regulatory competition between nation states has sharply increased (Scharpf 1997, Holzinger 2003), implying that we should expect an overall tendency towards an increasing similarity between national environmental policies.

Similar to the effects of international harmonisation, this general statement needs further qualification in light of the specific policy type. In this regard, we differentiate between policy items that are more or less likely to be affected by international trade. As trade-related policies, we classify product and process standards used in the production of internationally traded goods. Convergence should occur only for trade-related policies, as it is only this policy type that is subject to potential convergence pressures emerging from regulatory competition. By contrast, no convergence is predicted for policies subject to low competitive pressures from international markets. This holds true for all environmental policies that are not directly related to products or production processes, such as ambient quality standards, or nature protection.

\subsubsection{Direction of convergence}

In general, theories of regulatory competition predict that countries adjust regulatory standards downwards to cope with competitive pressures emerging from international economic integration. There is an ongoing debate in the literature whether this is true for all types of standards. A distinction is made between product and process standards (Scharpf 1997, Holzinger 2003). Typical examples of environmental product standards are car emission limit values; examples of process standards are limit values for the emissions of large combustion plants. In the case of process standards, we find a widely shared expectation that policy convergence will occur at the lowest common denominator (Drezner 2001). If the regulation of production processes implies an increase in the costs of production, potentially endangering the international 
competitiveness of an industry, regulatory competition will generally exert downward pressures on economic regulations (Scharpf 1997, p. 524).

Expectations are different for product standards. Industries in both lowregulating and high-regulating countries have a common interest in harmonising standards to avoid the costs of market segmentation; for example, the cost of producing and licensing different types of a product for different national markets. Whether the harmonisation occurs at the level of high-regulating or low-regulating countries depends on additional factors. Most important is the extent to which high-regulating countries are able actually to enforce stricter standards. If it is possible to erect exceptional trade barriers, convergence at a high level of regulation is likely (Scharpf 1997, p. 523). If such exceptional trade barriers cannot be justified, by contrast, competitive pressure is expected to induce governments to lower their environmental standards. Moreover, an upward move of regulatory levels can only be expected if the harmonisation advantage is valued more highly by business and governments than the cost difference between high and low levels of regulation (Holzinger 2003, p. 196). The classical example of a race to the top of product standards is car emission standards. When California raised its emission standards, other US states followed quickly (Vogel 1995). Apart from their own interest in better air quality, this has been interpreted as their reaction to the car manufacturer's interest in having the same standards everywhere. As the Californian car market is the biggest one in the United States, California's standards push the industry. As exceptional trade barriers can usually be justified in the environmental sector under EU and WTO rules, we expect regulatory competition should mostly lead to an upward shift of environmental regulation in case of product standards.

\subsubsection{Mobility: dynamics of catching-up}

According to theories of regulatory competition, both scenarios of catching-up and overtaking are conceivable. It is a constitutive element of regulatory competition theories that international economic integration leads to 'races' between the involved countries in attracting foreign capital and creating regulatory conditions that promote the competitiveness of domestic industries. Inherent to the notion of races are patterns of mutual overtaking or catchingup. If one or several countries lower environmental process standards to reduce the production costs for domestic companies, other countries will respond by adopting similar or even more far-reaching adjustments to safeguard their competitiveness. According to the theory, these mutual adjustments, and hence processes of catching-up and overtaking, continue until an equilibrium is reached in which all countries have reduced their standards to the lowest (or highest) possible level. As regulatory competition applies only to trade-related policies, for these regulations, falling back or catching-up should be more pronounced than for the others (Drezner 2001, Hoberg 2001, Simmons and Elkins 2003). 


\subsection{Conjectures on the homogeneity, direction and mobility}

Based on the above discussion of potential effects of international harmonisation and regulatory competition, the following conjectures on cross-national policy convergence in the environmental field can be derived.

\subsubsection{Policy homogeneity}

For policy homogeneity, both theoretical factors support an overall tendency towards increased similarity over time. They differ, however, with regard to the policy types for which these increases should be most pronounced.

Conjecture (1): Both theories of regulatory competition and international harmonisation suggest that there should be an overall increase in environmental policy homogeneity in the countries under study over time. Conjecture (2): From the discussion of international harmonisation effects it follows that homogeneity increases are more pronounced with regard to the adoption of policies than for the exact policy calibration (settings).

Conjecture (3): From the theory of regulatory competition it follows that homogeneity increases are more pronounced for trade-related policies than for non-trade-related policies.

Conjecture (4): From the discussion of international harmonisation it follows that homogeneity increases are more pronounced for obligatory than for non-obligatory policies.

\subsubsection{Direction of convergence}

Direction of convergence can only be established for policies that have exact settings related to the level of protection. We expect that international harmonisation effects generally lead to stringency increases, with the latter being most pronounced for obligatory policies, while any stringency decreases are very unlikely. This contrasts with the predicted effects of regulatory competition, where stringency decreases are expected for process standards. For product standards, the theory also predicts that stringency increases.

Conjecture (5): Regulatory stringency of product standards will increase; the same is true for process standards due to the effects of international harmonisation (5.1) whereas the opposite is expected for process standards due to the effects of regulatory competition (5.2).

Conjecture (6): Regulatory stringency increases will be more pronounced for obligatory standards than for non-obligatory policies.

\subsubsection{Mobility: dynamics of catching-up}

On the mobility dimension, the theories under consideration also predict effects of varying intensity according to different policy types. 
Conjecture (7): Processes of catching-up between countries are more pronounced for trade-related policies than for non-trade-related policies. Conjecture (8): Processes of catching-up between countries are more pronounced for obligatory than for non-obligatory policies.

\section{Empirical findings}

The assessment of policy convergence along the different dimensions is based on an analysis of domestic policy outputs (the policies adopted by a government) because the theories predict government decisions, which transform into environmental legislation. Policy outcomes (the actual effects of a policy in terms of goal achievement) are less suitable because they are only indirectly related to the causal mechanisms of convergence and are usually affected by many intervening variables.

We analyse the development of 22 environmental policy measures in the 24 countries under study between 1970 and 2005. The sample includes 19 EU member states from different rounds of EU enlargement, two European Free Trade Association (EFTA) members and Japan, Mexico and the United States (see Table 6). The policy items cover a broad range of different environmental sub-fields, representing all environmental media (e.g. air, water and waste), include different policy types as outlined in the theory section (e.g. traderelated and obligatory) and refer to both policy dimensions. ${ }^{2}$ The data are based on an update of the ENVIPOLCON data-set, which constitutes a highly encompassing collection of environmental output data. Binary data (adoption yes/no) for all 22 policy items are available at five points in time (1970, 1980, 1990, 2000 and 2005), while for the metrical data on 17 settings we are able to use a complete time series from 1970 to 2005 . The data have been collected (a) through a standardised questionnaire that has been completed by environmental policy experts for all countries and (b) through collecting and coding the respective environmental laws by the research team.

\subsection{Policy homogeneity}

Policy homogeneity refers to the extent to which the environmental policies of the countries under study have become more similar during the observation period. Homogeneity changes are assessed at two levels. First, we analyse the extent to which the policy repertoires of the countries converge. To what extent did the countries adopt the same policies? Second, we analyse the exact calibrations of the settings, such as limit values and recycling quotas. To what extent do the countries regulate environmental problems by similar levels of regulatory stringency? To assess whether the environmental policies of the 24 countries became more similar over time, we rely thus on two indicators: the adoption rates of 22 policies demonstrate convergence of the environmental policy repertoire, and a measure based on the pairwise similarity of countries provides us with information on the convergence of settings policies. 


\subsubsection{Convergence of policy repertoires}

Adoption rates capture the number (or percentage) of countries that have introduced a certain policy. Table 1 shows the development for the whole sample of 22 policies. We find a continuous spread of environmental policies across countries. In 2005, seven policies show an adoption rate of $100 \%$, that is, all 24 countries had adopted a measure in this field. For most policies, the number of adopting countries is above 20 , and in only one case is the adoption rate below $50 \%$ (efficient use of water in industry). The overall adoption rate in 2005 is $88.5 \%$.

The adoption numbers grew continuously over time. In 1970, there are only two policies that had already been adopted by 10 or more countries (noise emissions from lorries and industrial discharges). Ten years later, many

Table 1. Number of countries having adopted 22 policies, 19702005.

\begin{tabular}{|c|c|c|c|c|c|c|}
\hline & & 1970 & 1980 & 1990 & 2000 & 2005 \\
\hline Sulphur content in gas oil & $\mathrm{P}$ & 3 & 15 & 19 & 22 & 24 \\
\hline Lead in petrol & $\mathrm{P}$ & 6 & 15 & 23 & 24 & 24 \\
\hline Passenger cars emissions & $\mathrm{P}$ & 5 & 18 & 22 & 24 & 24 \\
\hline Hazardous substances in detergents & $\mathrm{P}$ & 4 & 10 & 17 & 19 & 21 \\
\hline Noise emissions standard from lorries & $\mathrm{P}$ & 10 & 19 & 22 & 23 & 24 \\
\hline Energy efficiency of refrigerators & $\mathrm{P}$ & 0 & 0 & 1 & 23 & 24 \\
\hline Eco labelling & $\mathrm{P}$ & 0 & 1 & 5 & 19 & 21 \\
\hline Large combustion plants emissions & $\mathrm{PP}$ & 4 & 13 & 19 & 23 & 23 \\
\hline Efficient use of water in industry & PP & 4 & 6 & 8 & 11 & 11 \\
\hline Industrial discharges in surface water & PP & 19 & 22 & 23 & 23 & 23 \\
\hline Recycling construction waste & PP & 0 & 0 & 1 & 11 & 14 \\
\hline Eco audit & $\mathrm{PP}$ & 0 & 0 & 1 & 16 & 19 \\
\hline Coliforms in bathing water & NPP & 2 & 12 & 22 & 24 & 24 \\
\hline Contaminated sites policy & NPP & 1 & 4 & 9 & 18 & 20 \\
\hline Soil protection & NPP & 2 & 4 & 10 & 16 & 17 \\
\hline Motorway noise emissions & NPP & 3 & 6 & 15 & 21 & 22 \\
\hline Waste recovery target & NPP & 0 & 0 & 4 & 18 & 22 \\
\hline Waste landfill target & NPP & 0 & 0 & 1 & 12 & 22 \\
\hline Glass reuse/recycling target & NPP & 0 & 0 & 2 & 15 & 20 \\
\hline Paper reuse/recycling target & NPP & 0 & 0 & 0 & 16 & 21 \\
\hline Environmental impact assessment & NPP & 1 & 2 & 17 & 24 & 24 \\
\hline Environmental/sustainable plan & NPP & 0 & 0 & 7 & 17 & 23 \\
\hline \multicolumn{7}{|l|}{ Mean number of countries } \\
\hline Product standards & & 4.00 & 11.14 & 15.57 & 22.00 & 23.14 \\
\hline Process standards & & 5.40 & 8.20 & 10.40 & 16.80 & 18.00 \\
\hline Non trade related policies & & 0.90 & 2.80 & 8.70 & 18.10 & 21.50 \\
\hline Obligatory policies & & 7.50 & 14.83 & 20.13 & 20.85 & 22.77 \\
\hline Non obligatory policies & & 2.45 & 3.63 & 6.21 & 16.44 & 19.00 \\
\hline All policies & & 2.91 & 6.68 & 11.27 & 19.05 & 21.23 \\
\hline
\end{tabular}

$\mathrm{P}$, product standard; PP, process standard; NPP, non trade related policy; obligatory items in bold. 
of the policies introduced by a few countries before 1970 had been adopted by more than half of the 24 countries. Some of the earliest introduced policies reached already (nearly) complete adoption in 2000 (e.g. lead in petrol). Finally, some policies showing up for the first time in 1990 reached high adoption rates rather quickly. Examples are energy efficiency of refrigerators, recycling targets or waste recovery targets. With respect to the policy repertoire of countries, we thus see a clear increase in homogeneity, which confirms Conjecture 1.

A breakdown according to the different policy subgroups in the lower part of Table 1 reveals that average adoption numbers vary across policy types as expected in Conjectures 3 and 4. First, average adoption numbers for product standards are clearly higher than for non-trade-related policies at all points in time. The pattern is similar for process standards, although the non-traderelated policies are catching-up in 2000 and 2005. This can be taken as a confirmation of Conjecture 3. Second, average adoption numbers for obligatory policies are continuously higher than that for non-obligatory policies. This confirms Conjecture 4 at the level of homogeneity of the policy repertoire.

\subsubsection{Homogeneity of settings}

Of the 22 policies of our sample, 17 specify limit values or similar metrical standards and allow for a more fine-tuned assessment of policy homogeneity across countries. To measure homogeneity, the regulatory level of each national setting is compared with that of all other countries in a pairwise manner and afterwards aggregated over all countries. The result is a homogeneity scale for every single settings policy: if two countries apply the exact same limit value, they get a score of $100 \%$; otherwise, the difference is expressed as a lower percentage. ${ }^{3}$

Table 2 gives the degree of homogeneity for all settings at the five points in time. First, when looking at average homogeneity for all 17 setting items (last row in Table 2), the numbers show a steady increase over time. From $0.5 \%$ in 1970 , similarity rises to $56.1 \%$ in 2005 , with the strongest period of growth during the 1990s. These results corroborate both Conjectures 1 and 2. First, they point to a strong tendency towards homogeneity in the regulatory level of policy settings, as well. Second, while convergence is clearly visible, the level of homogeneity among countries is lower for policy settings $(56.1 \%)$ than for the adoption of policies in general $(88.5 \%)$.

Moreover, the differences in the level of similarity between the subgroups of settings are more pronounced than for the adoption rates. Homogeneity is highest for product standards, with $90.5 \%$ in 2005 . In particular, the ban of lead in petrol and harmonisation of passenger car emissions have contributed to this trend. Over the entire period of observation, the level of similarity is lower when it comes to process standards, with a maximum of $41.1 \%$ in 2005 . In this group, homogeneity is highest with emission limits for large combustion 
Table 2. Pairwise similarity for 17 settings in percentage, 19702005.

\begin{tabular}{lrrrrrr}
\hline & & 1970 & 1980 & 1990 & 2000 & 2005 \\
\hline Sulphur content gas oil $(\mathrm{vol} \%)$ & $\mathrm{P}$ & 0.3 & $\mathbf{2 5 . 1}$ & $\mathbf{4 4 . 7}$ & $\mathbf{6 1 . 7}$ & $\mathbf{7 4 . 5}$ \\
Lead content in petrol $(\mathrm{g} / \mathrm{l})$ & $\mathrm{P}$ & 2.2 & $\mathbf{1 7 . 2}$ & $\mathbf{5 8 . 7}$ & $\mathbf{7 9 . 0}$ & $\mathbf{9 8 . 8}$ \\
Passenger car emissions CO $(\mathrm{g} / \mathrm{km})$ & $\mathrm{P}$ & $\mathbf{0 . 4}$ & $\mathbf{2 6 . 5}$ & $\mathbf{4 6 . 7}$ & $\mathbf{7 7 . 0}$ & $\mathbf{9 3 . 1}$ \\
Passenger car emissions $\mathrm{HC}(\mathrm{g} / \mathrm{km})$ & $\mathrm{P}$ & $\mathbf{0 . 0}$ & $\mathbf{3 0 . 2}$ & $\mathbf{5 0 . 7}$ & $\mathbf{7 4 . 9}$ & $\mathbf{9 1 . 9}$ \\
Passenger car emissions $\mathrm{NO}_{x}(\mathrm{~g} / \mathrm{km})$ & $\mathrm{P}$ & 0.0 & $\mathbf{1 5 . 4}$ & $\mathbf{4 3 . 7}$ & $\mathbf{6 9 . 8}$ & $\mathbf{9 1 . 3}$ \\
Noise emissions from lorries $(\mathrm{dB})$ & $\mathrm{P}$ & $\mathbf{3 . 4}$ & $\mathbf{3 5 . 8}$ & $\mathbf{5 6 . 1}$ & $\mathbf{6 9 . 5}$ & $\mathbf{9 3 . 4}$ \\
Large combustion plants $\mathrm{SO}_{2}\left(\mathrm{mg} / \mathrm{m}^{3}\right)$ & $\mathrm{PP}$ & 0.0 & 0.0 & $\mathbf{1 6 . 3}$ & $\mathbf{6 4 . 0}$ & $\mathbf{5 7 . 0}$ \\
Large combustion plants $\mathrm{NO}_{x}\left(\mathrm{mg} / \mathrm{m}^{3}\right)$ & $\mathrm{PP}$ & 0.0 & 0.0 & $\mathbf{9 . 7}$ & $\mathbf{5 0 . 1}$ & $\mathbf{3 9 . 4}$ \\
Large combustion plants dust $\left(\mathrm{mg} / \mathrm{m}^{3}\right)$ & $\mathrm{PP}$ & 0.0 & 0.0 & $\mathbf{1 6 . 3}$ & $\mathbf{5 7 . 6}$ & $\mathbf{5 6 . 1}$ \\
Lead in industrial discharges $(\mathrm{mg} / \mathrm{l})$ & $\mathrm{PP}$ & 0.4 & 8.5 & 30.1 & 35.8 & 40.9 \\
Copper in industrial discharges $(\mathrm{mg} / \mathrm{l})$ & $\mathrm{PP}$ & 0.3 & 6.2 & 26.5 & 34.7 & 39.5 \\
Zinc in industrial discharges $(\mathrm{mg} / \mathrm{l})$ & $\mathrm{PP}$ & 0.7 & 6.9 & 25.7 & 27.5 & 31.6 \\
Chromium in industrial discharges $(\mathrm{mg} / \mathrm{l})$ & $\mathrm{PP}$ & 0.4 & 6.8 & 27.7 & 37.6 & 42.9 \\
BOD in industrial discharges $(\mathrm{mg} / \mathrm{l})$ & $\mathrm{PP}$ & 0.0 & 6.5 & 13.6 & 17.5 & 23.9 \\
Motorway noise emissions $(\mathrm{dB})$ & $\mathrm{NPP}$ & 0.0 & 0.2 & 13.3 & 25.0 & 25.0 \\
Glass recycling target $(\%)$ & $\mathrm{NPP}$ & 0.0 & 0.0 & 0.0 & 13.6 & 26.5 \\
Paper recycling target $(\%)$ & $\mathrm{NPP}$ & 0.0 & 0.0 & 0.0 & 13.1 & 27.2 \\
Mean percentage & & & & & & \\
Product standards & & 1.1 & 25.0 & 50.1 & 72.0 & 90.5 \\
Process standards & & 0.2 & 4.4 & 20.7 & 40.6 & 41.4 \\
Non trade related settings & & 0.0 & 0.1 & 4.4 & 17.2 & 26.2 \\
Obligatory settings & & 1.3 & 25.0 & 38.1 & 67.1 & 77.3 \\
Non obligatory settings & & 0.3 & 3.2 & 17.1 & 25.6 & 32.2 \\
All settings & & 0.5 & 10.9 & 28.2 & 47.6 & 56.1 \\
\hline P & & & & & \\
\hline
\end{tabular}

$\mathrm{P}$, product standard; PP, process standard; NPP, non trade related policy; obligatory items in bold.

plants in 2005. The lowest degree of homogeneity can be observed for the nontrade-related policy settings, with an average similarity of only $26.2 \%$. Thus, Conjecture 3 is strongly corroborated by these results.

Similarly, the increase in homogeneity is stronger for obligatory settings than for regulatory standards without binding agreements at the international level. Obligatory standards converged from a modest level of $25 \%$ similarity in 1980 - when international harmonisation had just started - to $77.3 \%$ in 2005 . These include all six product standards, as well as three process standards from 1988 onwards, when the EU directive on emission limits for large combustion plants came into force. Average homogeneity of non-obligatory standards, however, amounts to only $32.2 \%$ in 2005 . Limit values on industrial discharges in surface water and noise emission standards along motorways, which have been present in many countries for a long time, show steady but slow convergence. Recycling targets for glass and paper, which had not been introduced before 1990, almost doubled their degree of homogeneity between 2000 and 2005, but at a modest level. This lends strong support to Conjecture 4. 
A closer look at the data reveals the extent to which the observed convergence has been caused by European harmonisation. Table 3 indicates the ratio of obligatory and non-obligatory convergent shifts in the sample of 24 countries. Overall, $52.2 \%$ of all regulatory changes that lead to cross-country convergence do not refer to the change of an obligatory $(=\mathrm{EU})$ environmental standard in an EU member state. Some standards have never been subject to EU harmonisation, in particular the standards for industrial discharges. The share of shifts of EU standards in non-member states is highest for noise emission standards for lorries $(44.50 \%)$, limit values for sulphur content in gas oil $(44.44 \%)$ and lead in petrol $(38.11 \%)$.

On the one hand, the results from Table 3 confirm our finding that convergence is more pronounced for regulatory standards with binding agreements at the international level. On the other hand, they reveal that the phenomenon of environmental policy convergence is not attributable to EU mandates alone, and thus support the interpretation of policy homogeneity as a more general trend among OECD countries.

\subsection{Policy direction}

To what extent have environmental policies in the countries under study become stricter during the observation period? Was increasing policy homogeneity on average accompanied by an increase or decrease in levels of regulation? To answer this question, we analyse the development of the

Table 3. Percentage of non EU related convergent shifts, 17 settings, 19702005.

\begin{tabular}{lcc}
\hline & & Convergent shifts $(\%)$ \\
\hline Sulphur content gas oil (vol \%) & $\mathrm{P}$ & 44.44 \\
Lead content in petrol $(\mathrm{g} / \mathrm{l})$ & $\mathrm{P}$ & 38.11 \\
Passenger car emissions CO $(\mathrm{g} / \mathrm{km})$ & $\mathrm{P}$ & 22.78 \\
Passenger car emissions $\mathrm{HC}(\mathrm{g} / \mathrm{km})$ & $\mathrm{P}$ & 26.87 \\
Passenger car emissions $\mathrm{NO}_{x}(\mathrm{~g} / \mathrm{km})$ & $\mathrm{P}$ & 20.41 \\
Noise emissions from lorries $(\mathrm{dB})$ & $\mathrm{P}$ & 44.50 \\
Large combustion plants $\mathrm{SO}_{2}\left(\mathrm{mg} / \mathrm{m}^{3}\right)$ & $\mathrm{PP}$ & 27.37 \\
Large combustion plants $\mathrm{NO}_{x}\left(\mathrm{mg} / \mathrm{m}^{3}\right)$ & $\mathrm{PP}$ & 24.82 \\
Large combustion plants dust $\left(\mathrm{mg} / \mathrm{m}^{3}\right)$ & $\mathrm{PP}$ & 27.21 \\
Lead in industrial discharges $(\mathrm{mg} / \mathrm{l})$ & $\mathrm{PP}$ & 100.00 \\
Copper in industrial discharges $(\mathrm{mg} / \mathrm{l})$ & $\mathrm{PP}$ & 100.00 \\
Zinc in industrial discharges $(\mathrm{mg} / \mathrm{l})$ & $\mathrm{PP}$ & 100.00 \\
Chromium in industrial discharges $(\mathrm{mg} / \mathrm{l})$ & $\mathrm{PP}$ & 100.00 \\
BOD in industrial discharges $(\mathrm{mg} / \mathrm{l})$ & $\mathrm{PP}$ & 100.00 \\
Motorway noise emissions $(\mathrm{dB})$ & $\mathrm{NPP}$ & 7.03 \\
Glass recycling target $(\%)$ & $\mathrm{NPP}$ & 3.36 \\
Paper recycling target $(\%)$ & $\mathrm{NPP}$ & 52.20 \\
$\quad$ Mean percentage & & \\
\hline
\end{tabular}

P, product standard; PP, process standard; NPP, non trade related policy. 
regulatory mean over time. Table 4 displays the changes of the regulatory mean of the 17 settings since 1970 . The trend is indicated by a ' + ', ' 0 ' or '[minus]' in the last column. The different units of measurement do not allow for a comparison of different groups of settings.

Our empirical findings indicate a general trend towards increasing regulatory strictness over time. This pattern is most pronounced for all six product standards, for which a strengthening can be observed throughout the whole observation period. These results confirm the first part of Conjecture 5, which predict an upward move for products standards based on considerations of international harmonisation and regulatory competition.

With respect to the second part of the conjecture, the picture is different. Whereas international harmonisation foresees an upward move for process

Table 4. Regulatory mean of 17 settings, 19702005.

\begin{tabular}{|c|c|c|c|c|c|c|}
\hline & 1970 & 1980 & 1990 & 2000 & 2005 & Change \\
\hline Sulphur content gas oil (vol \%) & 1.47 & 0.61 & 0.40 & 0.27 & 0.26 & + \\
\hline Lead content in petrol $(\mathrm{g} / \mathrm{l})$ & 0.61 & 0.38 & 0.18 & 0.06 & 0.01 & + \\
\hline $\begin{array}{l}\text { Passenger car emissions } \\
\text { CO }(\mathrm{g} / \mathrm{km})\end{array}$ & 34.10 & 29.72 & 5.69 & 2.68 & 2.50 & + \\
\hline $\begin{array}{l}\text { Passenger car emissions } \\
\mathrm{HC}(\mathrm{g} / \mathrm{km})\end{array}$ & 6.90 & 2.29 & 0.74 & 0.28 & 0.26 & + \\
\hline $\begin{array}{l}\text { Passenger car emissions } \\
\mathrm{NO}_{x}(\mathrm{~g} / \mathrm{km})\end{array}$ & & 2.96 & 0.79 & 0.30 & 0.21 & + \\
\hline $\begin{array}{l}\text { Noise emissions from } \\
\text { lorries }(\mathrm{dB})\end{array}$ & 90.83 & 89.11 & 85.18 & 80.91 & 80.21 & + \\
\hline $\begin{array}{l}\text { Large combustion plants } \\
\mathrm{SO}_{2}\left(\mathrm{mg} / \mathrm{m}^{3}\right)\end{array}$ & & 1625.00 & 581.82 & 461.90 & 385.71 & + \\
\hline $\begin{array}{l}\text { Large combustion plants } \\
\mathrm{NO}_{x}\left(\mathrm{mg} / \mathrm{m}^{3}\right)\end{array}$ & & & 515.00 & 552.38 & 388.10 & + \\
\hline $\begin{array}{l}\text { Large combustion plants } \\
\text { dust }\left(\mathrm{mg} / \mathrm{m}^{3}\right)\end{array}$ & & 150.00 & 50.00 & 74.09 & 58.64 & + \\
\hline $\begin{array}{l}\text { Lead in industrial } \\
\text { discharges }(\mathrm{mg} / \mathrm{l})\end{array}$ & 3.40 & 0.34 & 0.54 & 0.51 & 0.51 & + \\
\hline $\begin{array}{l}\text { Copper in industrial } \\
\text { discharges }(\mathrm{mg} / \mathrm{l})\end{array}$ & 9.00 & 0.83 & 1.06 & 1.33 & 1.25 & 0 \\
\hline $\begin{array}{l}\text { Zinc in industrial } \\
\text { discharges }(\mathrm{mg} / \mathrm{l})\end{array}$ & 2.67 & 2.21 & 2.39 & 3.44 & 3.39 & 0 \\
\hline $\begin{array}{l}\text { Chromium in industrial } \\
\text { discharges }(\mathrm{mg} / \mathrm{l})\end{array}$ & 17.00 & 1.30 & 1.79 & 1.56 & 1.53 & + \\
\hline $\begin{array}{l}\text { BOD in industrial } \\
\text { discharges }(\mathrm{mg} / \mathrm{l})\end{array}$ & 4.00 & 30.88 & 46.00 & 51.92 & 46.33 & \\
\hline $\begin{array}{l}\text { Motorway noise } \\
\text { emissions }(\mathrm{dB})\end{array}$ & & 52.50 & 55.33 & 53.27 & 53.27 & 0 \\
\hline $\begin{array}{l}\text { Glass recycling } \\
\text { target }(\%)\end{array}$ & & & & 54.00 & 53.05 & + \\
\hline $\begin{array}{l}\text { Paper recycling } \\
\text { target }(\%)\end{array}$ & & & & 49.79 & 49.00 & + \\
\hline
\end{tabular}

Obligatory items in bold. 
standards (5.1), the theory of regulatory competition predicts a race to the bottom (5.2). The latter is not mirrored by the data. With minor exceptions, the upward trend towards stricter regulation also holds for process standards as well as for three standards not related to trade. Limit values for biological oxygen demand (BOD) in industrial discharges are the only standard with a tendency towards less stricter values. However, this development comes along with an increasing rate of adoption (see Table 1), so that the decrease in the mean can be attributed to new introductions in less ambitious countries. Moreover, this is a case in which scientific uncertainty was high and, therefore, limit values varied widely. Overall, our findings provide no support for the race to the bottom scenarios developed in theories of regulatory competition.

Finally, as expected in Conjecture 6, the level of strictness increases more strongly for obligatory policies (bold figures) than for non-obligatory ones. That is, international harmonisation seems to go along with upward moves in the level of stringency. This includes both product and process standards harmonised at the EU level.

\subsection{Mobility changes}

The mobility dimension addresses the question whether and to what extent laggard countries were catching-up or overtaking the frontrunners over time with regard to the strictness of their environmental regulations, or, the other way round, to what extent former leaders fell back. To account for such dynamics, we apply two concepts. First, we measure the extent to which processes of catching-up occurred. The concept of beta convergence is based on a comparison of growth coefficients (beta), which is, in our context, equivalent to the strengthening or relaxation of regulatory standards during the next period of time. Second, we compare the change in country rankings over time. This allows us to make statements on the extent to which a process of catchingup coincided with actual overtaking of the frontrunners by the laggards (Heichel et al. 2005, p. 831-833).

\subsubsection{Catching-up}

To provide an overview of the extent to which we can observe processes of catching-up among the 24 countries, we assess beta convergence on the basis of bivariate regressions. The growth rate is estimated solely on the basis of the previous level of regulation. A positive coefficient is equivalent to a process of catching-up. In these cases, countries with less-stringent environmental regulations strengthened their policies to a higher degree than former frontrunner countries. As displayed in Table 5, for most environmental standards, the regression reveals significant results, which is equivalent of a catching-up of laggards. Only for 4 of the 17 items we do not find beta convergence: zinc and BOD in industrial discharges, motorway noise emission limits and paper recycling quotas. As two of them are not trade-related, this 
Table 5. Beta convergence of 17 settings, 19702005.

\begin{tabular}{|c|c|c|c|c|}
\hline & 19701980 & 19801990 & 19902000 & 20002005 \\
\hline $\begin{array}{l}\text { Sulphur content } \\
\text { gas oil (vol \%) }\end{array}$ & & $0.97 * *$ & $1.05^{* * *}$ & $0.21 *$ \\
\hline Lead content in petrol $(\mathrm{g} / \mathrm{l})$ & & $0.87 * *$ & $1.02 * *$ & $0.75 * *$ \\
\hline $\begin{array}{l}\text { Passenger car emissions } \\
\mathrm{CO}(\mathrm{g} / \mathrm{km})\end{array}$ & & $0.85^{* *}$ & $1.13 * *$ & $0.98 * *$ \\
\hline $\begin{array}{l}\text { Passenger car emissions } \\
\mathrm{HC}(\mathrm{g} / \mathrm{km})\end{array}$ & 0.35 & $0.47 * *$ & $0.44 * *$ & $1.01 * *$ \\
\hline $\begin{array}{l}\text { Passenger car emissions } \\
\mathrm{NO}_{x}(\mathrm{~g} / \mathrm{km})\end{array}$ & $0.61 * *$ & $0.62^{* * *}$ & $0.31 * *$ & 0.04 \\
\hline $\begin{array}{l}\text { Noise emissions from } \\
\text { lorries }(\mathrm{dB})\end{array}$ & 1.20 & $0.74 * *$ & $0.45^{* * *}$ & $0.92 * *$ \\
\hline $\begin{array}{l}\text { Large combustion plants } \\
\qquad \mathrm{SO}_{2}\left(\mathrm{mg} / \mathrm{m}^{3}\right)\end{array}$ & & 0.29 & $0.98 * *$ & 0.04 \\
\hline $\begin{array}{l}\text { Large combustion plants } \\
\mathrm{NO}_{x}\left(\mathrm{mg} / \mathrm{m}^{3}\right)\end{array}$ & & & & $0.27 * *$ \\
\hline $\begin{array}{l}\text { Large combustion plants } \\
\text { dust }\left(\mathrm{mg} / \mathrm{m}^{3}\right)\end{array}$ & & & 0.14 & $0.52 * *$ \\
\hline $\begin{array}{l}\text { Lead in industrial } \\
\text { discharges }(\mathrm{mg} / \mathrm{l})\end{array}$ & $0.99 * *$ & 0.03 & 0.27 & 0.06 \\
\hline $\begin{array}{l}\text { Copper in industrial } \\
\text { discharges }(\mathrm{mg} / \mathrm{l})\end{array}$ & $0.97 * *$ & 0.27 & $0.34 * *$ & 0.01 \\
\hline $\begin{array}{l}\text { Zinc in industrial } \\
\text { discharges }(\mathrm{mg} / \mathrm{l})\end{array}$ & 0.52 & 0.28 & 0.84 & \\
\hline $\begin{array}{l}\text { Chromium in industrial } \\
\text { discharges }(\mathrm{mg} / \mathrm{l})\end{array}$ & $0.92 * *$ & 0.21 & 0.32 & 0.02 \\
\hline $\begin{array}{l}\text { BOD in industrial } \\
\text { discharges }(\mathrm{mg} / \mathrm{l})\end{array}$ & & & 0.10 & 0.01 \\
\hline $\begin{array}{l}\text { Motorway noise } \\
\text { emissions }(\mathrm{dB})\end{array}$ & & & 0.37 & \\
\hline $\begin{array}{l}\text { Glass recycling } \\
\text { target }(\%)\end{array}$ & & & & $0.25^{*}$ \\
\hline $\begin{array}{l}\text { Paper recycling } \\
\text { target }(\%)\end{array}$ & & & & 0.03 \\
\hline
\end{tabular}

Obligatory items in bold; ${ }^{*} p<0.10,{ }^{* *} p<0.05$ (two tailed).

can be interpreted as confirmation of Conjecture 7. Similarly, the figures in Table 5 support Conjecture 8 stating that more catching-up will take place with obligatory than with non-obligatory policies.

\subsubsection{Changing ranks}

In addition to the identification of processes of catching-up of laggards, we analyse the extent to which the countries actually changed their ranks in terms of weighted regulatory strictness over time. ${ }^{4}$ Catching-up may, but need not necessarily, mean overtaking of other countries. With regard to homogeneity, we might interpret a process of growing together that coincides with a complete overthrow of country rankings differently from a situation in which national 
Table 6. Country ranking by regulatory strictness and scope, 19702005.

\begin{tabular}{lrrrrr}
\hline & 1970 & 1980 & 1990 & 2000 & 2005 \\
\hline Austria & 12 & 16 & 7 & 3 & 6 \\
Belgium & 8 & 9 & 8 & 6 & 11 \\
Bulgaria & 13 & 17 & 20 & 19 & 21 \\
Denmark & 17 & 6 & 10 & 7 & 10 \\
Finland & 6 & 14 & 15 & 10 & 4 \\
France & 2 & 1 & 4 & 4 & 5 \\
Germany & 5 & 3 & 5 & 2 & 2 \\
Greece & 17 & 23 & 22 & 21 & 20 \\
Hungary & 18 & 15 & 16 & 15 & 13 \\
Ireland & 24 & 18 & 18 & 16 & 14 \\
Italy & 10 & 5 & 3 & 5 & 8 \\
Japan & 1 & 2 & 1 & 9 & 7 \\
Mexico & 24 & 24 & 21 & 24 & 24 \\
The Netherlands & 10 & 7 & 2 & 1 & 1 \\
Norway & 24 & 21 & 9 & 13 & 15 \\
Poland & 17 & 20 & 19 & 22 & 19 \\
Portugal & 22 & 23 & 18 & 18 \\
Romania & 24 & 19 & 24 & 23 & 22 \\
Slovakia & 17 & 13 & 17 & 20 & 17 \\
Spain & 20 & 11 & 14 & 14 & 16 \\
Sweden & 19 & 4 & 11 & 8 & 3 \\
Switzerland & 3 & 12 & 6 & 11 & 12 \\
UK & 7 & 8 & 13 & 12 & 9 \\
USA & 11 & & 12 & 17 & 23 \\
\hline
\end{tabular}

limit values get similar over time, but with pioneer and laggard countries holding their rank positions. For this purpose, country-rankings based on the strictness of 17 domestic environmental standards are compared over time.

Table 6 shows the country rankings for 1970, 1980, 1990, 2000 and 2005. First, it becomes apparent that there is a visible degree of mobility. Former forerunners like Japan and the United States cannot keep pace with the spread of environmental policies elsewhere and fall behind during the 1990s. Other countries, for example Austria and the Netherlands, have changed from laggards in the 1970s to frontrunner states in the 1990s. However, several countries do not seem to alter their role. Pioneer countries like Germany and France conserve their top positions over time, whereas environmental laggards, such as Mexico, Romania or Greece are still at the bottom of the ranking in 2005. Thus, although we observe a general tendency of catching-up, not all countries took part in this development. This does not imply, however, that they did not strengthen their environmental policies at all.

\section{Conclusion}

In terms of the increasing homogeneity of environmental policies in our country sample, all four conjectures have been confirmed. From the analysis of 
policy adoptions, we saw that there is a general trend of convergence. Compared with the overall trend, the degree of convergence is lower with respect to exact policy settings. As expected, homogeneity increased more strongly for obligatory policies than for non-obligatory ones, and more strongly for trade-related policies than for non-trade-related ones.

In terms of the direction, we found a surprisingly clear pattern of upward movement. For the settings, we observe a clear increase in regulatory strictness. The level of protection has risen considerably over time, as has been shown by the development of the regulatory mean for settings policies. As expected, the rise in strictness is more pronounced for obligatory policies than for nonobligatory ones. It is also more pronounced for trade-related policies than for non-trade-related policies. However, we observe not only a general upward movement for product, but also for process standards. This finding is in line with the theory of international cooperation, but clearly contradicts the theory of regulatory competition.

The picture is similar when it comes to the mobility aspect. There is a general trend of catching-up by laggard countries for almost all policies. Moreover, mobility is clearly higher for trade-related policies and for obligatory policies than for those policies not related to international trade and not harmonised at the international level. Despite an overall tendency of catching-up and an overall increase in regulatory strictness, we observe a number of countries that seem stuck at the bottom of the country ranking.

From these observations, we can infer that processes of globalisation and, in particular, increasing political integration through international cooperation and harmonisation of policies, in general, stimulate the development and adoption of environmental policies, lead to their convergence and drive the level of protection upwards. We clearly observe an increase in the number of individual environmental policies countries apply, an increase in the homogeneity of the countries' policy repertoires, an increase in the homogeneity of individual policies across countries, a strong increase in the strictness of regulations, as well as processes of catching-up and overtaking among countries. The fear that economic globalisation leads to competition in regulatory laxness is not justified, at least not for our sample of OECD countries. If these pressures exist at all, they are obviously counteracted by international cooperation.

Two limitations of this study have to be mentioned, however. The first concerns our sample of 24 OECD countries. The results cannot be generalised beyond the OECD world, as we did not include important countries, such as Brazil, China or India. The countries in our sample are similar in terms of their economic development, and they are democracies responsive to the demands of environmentally friendly populations. We cannot exclude the possibility that dirty production processes have been shifted to non-OECD states in the developing world or in emerging markets.

Moreover, most countries of the sample are now EU member states and, thus, are subject to EU harmonisation policies. It should be considered, 
however, that this applied to only 11 of the 24 countries in 1990. For the first 20 years of our study, Eastern and Southern European countries were much less developed and democratic. Second, our analysis uses output data for good reasons. This implies, however, that we do not know what happens during implementation (Knill et al. 2008). It is, thus, important for future research to compare our results with the development of environmental outcome data.

Our main goal lies in measuring and explaining policy convergence, not in evaluating this process. However, a few words are in order. We see the impressive amount of convergence as a process of globalisation of politics in which states commonly adopt rules regulating and correcting the globalising markets and in which they learn from one another how to best achieve this. The findings concerning the direction of convergence and on mobility show clearly that becoming more homogenous does not imply a slowing down of innovation. New problems seem to have been tackled by pioneer states, and the solutions have been taken over by others states and by supra- or international regimes. All in all, we thus judge the convergence process in environmental policy as a positive development.

\section{Acknowledgements}

This article is based on two research projects: 'Environmental Governance in Europe', an FP 5 project funded by the European Commission (contract no. HPSE-CT-2002-00103) since 2003, and 'Factors of Policy Change', funded by the German Science Foundation (DFG) since 2006.

\section{Notes}

1. Following Popper's (1963) definition, we use the term 'conjecture' to indicate a proposition that is presumed to be real, true or genuine, mostly based on inconclusive grounds, in contrast with the term 'hypothesis', which is a testable statement based on accepted grounds.

2. A list of the 22 policy items is provided in Table 1 .

3. For details of measurement, see Holzinger et al. (2008b). The non existence of a setting in two countries is classified as dissimilarity.

4. To get a more balanced result, we weighted the regulatory stringency with the number of policies adopted. If this correction were not introduced, a country with only a single but strict policy would be overestimated with regard to changes in the stringency of environmental standards.

\section{References}

Barrios, S., Görg, H., and Strobl, E., 2003. Multinational enterprises and new trade theory: evidence for the convergence hypothesis. Open Economies Review, 14 (4), 397418.

Bennett, C., 1991. What is policy convergence and what causes it? British Journal of Political Science, 21 (2), 215233.

Busch, P. O., Jörgens, H., and Tews, K., 2005. The global diffusion of regulatory instruments: the making of a new international environmental regime. The Annals of the American Academy of Political and Social Science, 598 (1), 146167. 
Dimitrova, A. and Steunenberg, B., 2000. The search for convergence of national policies in the European Union. An impossible quest? European Union Politics, 1 (2), 201226.

Drezner, D., 2001. Globalization and policy convergence. The International Studies Review, 3 (1), 5378

Guillén, M., 2001. Is globalization civilizing, destructive of feeble? A critique of five key debates in the social science literature. Annual Review of Sociology, 27, 235 260

Hall, P.A., 1993. Policy paradigms, social learning and the state. The case of economic policymaking in Britain. Comparative Politics, 25, 275296.

Heichel, S., Pape, J., and Sommerer, T., 2005. Is there convergence in convergence research? Journal of European Public Policy, 12 (5), 817840.

Héritier, A., Knill, C., and Mingers, S., 1996. Ringing the changes in Europe. Regulatory competition and the transformation of the state. Berlin: de Gruyter.

Hoberg, G., 2001. Globalization and policy convergence: symposium overview. Journal of Comparative Policy Analysis: Research and Practice, 3 (2), 127132.

Holzinger, K., 2003. Common goods, matrix games, and institutional solutions. European Journal of International Relations, 9, 173212.

Holzinger, K., 2006. Methodological pitfalls of convergence analysis. European Union Politics, 7, 271287.

Holzinger, K. and Knill, C., 2004. Regulatory competition and regulatory cooperation in environmental policy: individual and interaction effects. Journal of Public Policy, $24,2547$.

Holzinger, K. and Knill, C., 2005. Causes and conditions of cross national policy convergence. Journal of European Public Policy, 12, 775796.

Holzinger, K. and Knill, C., 2008. The interaction of competition, co operation and communication: theoretical analysis of different sources of environmental policy convergence. Journal of Comparative Policy Analysis: Research and Practice, 10 (4), 403425.

Holzinger, K., Knill, C., and Arts, B., eds., 2008a. Environmental policy convergence in Europe: the impact of international institutions and trade. Cambridge: Cambridge University Press.

Holzinger, K., Knill, C., and Sommerer, T., 2008b. Environmental policy convergence. The impact of international harmonization, transnational communication and regulatory competition. International Organization, 62 (4), 553587.

Jahn, D., 2006. Globalization as Galton's problem: the missing link in the analysis of diffusion patterns in welfare state development. International Organization, 60 (2), 401431.

Kahler, M. and Lake, D., 2003. Governance in a global economy. Princeton, NJ: Princeton University Press.

Knill, C., 2001. The Europeanisation of national administrations. Cambridge: Cambridge University Press.

Knill, C., 2003. Europäische Umweltpolitik. Steuerungsprobleme und Regulierungsmuster im Mehrebenensystem. Opladen: Leske und Budrich.

Knill, C., 2008. Europäische Umweltpolitik. Steuerungsprobleme und Regulierungsmuster im Mehrebenensystem. Opladen: Leske und Budrich.

Knill, C., Tosun, J., and Heichel, S., 2008. Balancing competitiveness and conditionality: environmental policy making in low regulating countries. Journal of European Public Policy, 15 (7), 10191040.

Martin, L. and Simmons, B.A., 1998. Theories and empirical studies of international institutions. International Organization, 52 (4), 729757.

Meyer, J., et al., 1997. World society and the nation state. American Journal of Sociology, 103 (1), 144181. 
Oates, W. and Schwab, R., 1988. Economic competition among jurisdictions. Efficiency enhancing or distortion inducing? Journal of Public Economics, 35, 333354.

Popper, K., 1963. Conjectures and refutations: the growth of scientific knowledge. London: Routledge.

Scharpf, F., 1997. Introduction. The problem solving capacity of multi level govern ance. Journal of European Public Policy, 4 (4), 520538.

Simmons, B. and Elkins, Z., 2003. Globalization and policy diffusion: explaining three decades of liberalization. In: M. Kahler and D. Lake, eds. Globalizing authority: economic integration and the changing structure of governance. Princeton, NJ: Princeton University Press, 275302.

Swank, D., 2006. Tax policy in an era of internationalization: explaining the spread of neoliberalism. International Organization, 60 (4), 847882.

Vogel, D., 1995. Trading up. Consumer and environmental regulation in the global economy. Cambridge: Harvard University Press.

Volden, C., 2006. States as policy laboratories: emulating success in the children's health insurance program. American Journal of Political Science, 50 (2), 294312.

Zürn, M., 1998. The rise of international environmental politics: a review of current research. World Politics, 50 (4), 137144. 